\title{
International Journal of
}

\section{Clinical Obstetrics and Gynaecology}

ISSN (P): 2522-6614

ISSN (E): 2522-6622

(C) Gynaecology Journal

www.gynaecologyjournal.com

2021; 5(6): 176-178

Received: 20-09-2021

Accepted: 25-10-2021

\section{Dr. Shirly Kurian}

Associate Professor, Department of OBG, Mount Zion Medical College,

Chayalode, Adoor, Kerala, India

Dr. Mallikarjuna M

Professor, Department of OBG,

Mount Zion Medical College,

Chayalode, Adoor, Kerala, India

Corresponding Author:

Dr. Mallikarjuna M

Professor, Department of OBG

Mount Zion Medical College,

Chayalode, Adoor, Kerala, India

\section{A Descriptive clinical study on Placenta Praevia at a tertiary care hospital}

\section{Dr. Shirly Kurian and Dr. Mallikarjuna M}

DOI: https://doi.org/10.33545/gynae.2021.v5.16c.1079

\begin{abstract}
Aetiology of placenta praevia is obscure. It is caused by low implantation of the blastocyst at a site low in uterine cavity. The cause of low implantation is unknown, but certain factors are known to predispose to development of placenta praevia. All patients who came with history of painless bleeding per vagina after 28 weeks of gestation were hospitalized. A thorough history of vaginal bleeding (warning haemorrhage) was taken .Cases with confirmed diagnosis of placenta praevia on ultrasonography were included in the study. Placental anomalies were present in 4 ( 4.76 percent) cases, out of which, 2 cases ( 2.38 percent) were of adherent placenta. Placenta was removed in piece meal and PPH was controlled by bimanual compression and injection prostodin and methergin.
\end{abstract}

Keywords: Placenta Praevia, Warning Haemorrhage, Painless Bleeding

\section{Introduction}

At full term, the placenta has a discoid shape, a diameter of $15-25 \mathrm{~cm}$, is approximately $3 \mathrm{~cm}$ thick, and has a weight of about 500-600gm. At birth, it is torn from the uterine wall and approximately 30 minutes after birth of the child, is expelled from the uterine cavity. When, after birth, the placenta is viewed from the maternal side, 15-20 slightly bulging areas, the cotyledons, covered by a thin layer of decidua basal is are clearly recognizable. Grooves between the cotyledon are formed by decidual septa. Much of the decidua remains temporarily in the uterus and is expelled with subsequent uterine bleeds ${ }^{[1,2]}$.

The fetal surface of the placenta is covered entirely by the chorionic plate. A number of large arteries and veins, the chorionic vessels, converge toward the umbilical cord. The chorion in turn, is covered by the amnion. Attachment of the umbilical cord is usually eccentric and occasionally even marginal. Rarely, however it does insert into the chorionic membranes outside the placenta ${ }^{[3,4]}$.

Aetiology of placenta praevia is obscure. It is caused by low implantation of the blastocyst at a site low in uterine cavity. The cause of low implantation is unknown, but certain factors are known to predispose to development of placenta praevia. Two forms of implantation have been described, (a) primary is thmial implantation (b) secondary is thmial implantation. Cases of cervical pregnancies were reported.

The fertilized ovum drops down and is implanted in LUS, Poor decidual reaction in UUS or a delayed implantation maybe the cause. Defective decidua and multiple pregnancy, with large placental surface predisposes to lower implantation. Incidence of recurrence is 12 fold according to Eastman ${ }^{[5,6]}$.

\section{Methodology}

During this study period 8633 cases were delivered. Among these 84 cases were identified as having placenta praevia.

All patients who came with history of painless bleeding per vagina after 28 weeks of gestation were hospitalized. A thorough history of vaginal bleeding (warning haemorrhage) was taken. Cases with confirmed diagnosis of placenta praevia on ultrasonography were included in the study. If patients had come in emergency without USG, diagnosis of placenta praevia was confirmed by per vaginal examination or examination of the placenta after the delivery, were included in the study. Cases which presented below 28 weeks of gestation, with confirmed diagnosis of abruptio placenta or local lesions of vagina and cervix or patients in preterm labour 
without confirmed placenta praevia were excluded from the study.

Those cases who came with history of painless bleeding per vagina or warning haemorrhage after 28 weeks of gestation were admitted in the hospital. USG was done, if found to be placenta praevia, with live premature fetus, haemodynamically stable, with no or minimal bleeding and not in established labour were managed expectantly with tocolytics, antibiotics, steroids and bed rest. Anaemia was defined as haemoglobin $<10 \mathrm{gm} \%$ or haematocrit $<30 \%$. If found to be anaemic, depending on the degree of anaemia, correction was done with either blood transfusion or parenteral iron therapy. This expectant management was continued till term or maturity of fetus and later taken for elective $\mathrm{C} / \mathrm{S}$. If patient develops severe bout of bleeding then emergency $\mathrm{C} / \mathrm{S}$ was done irrespective of the maturity. Occassionally if patient is in established labour, with minimal bleed, good general condition and minor degree of placenta praevia, vaginal delivery was allowed.

If the patient is admitted in emergency with severe painless bleeding per vaginum without any previous USG, and is in shock, resuscitative measures were carried out in the form of IV fluids, blood transfusion and antibiotics. Vaginal examination was done in a "double set up" condition, if turns out as placenta praevia, then emergency $\mathrm{C} / \mathrm{S}$ was done. Placenta was examined to confirm the diagnosis whether delivered vaginally or by $\mathrm{C} / \mathrm{S}$.

\section{Results}

Table 1: Ultrasound in Placenta Praevia

\begin{tabular}{|c|c|c|}
\hline USG & No. of cases & Percentage \\
\hline Done & 52 & 61.90 \\
\hline Not done & 32 & 38.10 \\
\hline Total & 84 & 100 \\
\hline
\end{tabular}

The above table shows that, only in 52 (61.90 percent) cases USG was done before delivery and placenta praevia confirmed. In the remaining 32 (38.10 percent) placenta praevia was confirmed either by PV examination or during $\mathrm{C} / \mathrm{S}$ or by retrospective inspection of placenta after delivery.

Table 2: Sensitivity and specificity of USG in Placenta Praevia

\begin{tabular}{|c|c|c|}
\hline Ultrasound & No. of cases & Percentage \\
\hline Done & 52 & 61.90 \\
\hline False positive & 0 & -- \\
\hline False negative & 2 & 3.85 \\
\hline
\end{tabular}

The above table shows, out of 52 cases of USG done placenta praevia was not diagnosed in 2 cases giving false negative rate of 3.85 percent.

USG is a quick, safe and accurate mode of localizing placenta and also the fetal well-being. It has greatly influenced the management of placenta praevia and also the maternal and perinatal outcome ${ }^{[6]}$.

Table 3: APGAR score in placenta praevia

\begin{tabular}{|c|c|c|c|}
\hline Sl. No. & APGAR & No. of babies & Percentage \\
\hline 1 & Good & 35 & 41.67 \\
\hline 2 & Poor & 20 & 23.81 \\
\hline 3 & Absent & 29 & 34.52 \\
\hline Total & & 84 & 100 \\
\hline
\end{tabular}

The above table shows that out of 84 babies, 35 (41.67 percent) babies were born with good APGAR score. 29 (34.52 percent) babies did not show any sign of life and the remaining 20 (23.81 percent) were born with poor APGAR, out of which 11 survived till $8^{\text {th }}$ postoperative day and 9 died by $4^{\text {th }}$ postnatal day.

Table 4: Placental Anomalies in Placenta praevia

\begin{tabular}{|c|c|c|c|}
\hline Sl. No. & Placenta anomaly & Number of cases & Percentage \\
\hline 1. & Adherent placenta & 2 & 2.38 \\
\hline 2. & Placenta increate & 1 & 1.19 \\
\hline 3. & Succenturate lobe & 1 & 1.19 \\
\hline Total & & 4 & 4.76 \\
\hline
\end{tabular}

The above table shows that placental anomalies were present in 4 (4.76 percent) cases, out of which, 2 cases ( 2.38 percent) were of adherent placenta. Placenta was removed in piece meal and PPH was controlled by bimanual compression and injection prostodin and methergin.

In 1 case (1.19 percent), placenta was adherent to posterior wall of the bladder wall, subtotal hysterectomy was done. In 1 (1.19 percent) case succenturate lobe was found in the LUS. Placental pathologies are known to be associated and hence increase the incidence of placenta praevia.

\section{Discussion}

Placenta praevia has a classic presentation of painless vaginal bleeding. Pain may be a feature of the initial presentation and suggests the possibility of concurrent placental abruption or the onset of painful contraction. The degree of bleeding is variable from slight spotting of fresh blood to a torrential haemorrhage. However, the first warning bleed from placenta praevia is rarely severe and delivery may be safely delayed for a period of time in most cases.

The management of a women with bleeding from a placenta praevia will depend on 2 main factors. The degree of haemorrhage and the fetal maturity at the time of haemorrhage. Absolute indications for delivery include, bleeding of any type at fetal maturity, fetal distress at viable gestations and persistant haemorrhage causing maternal haemodynamic instability at any stage in pregnancy ${ }^{[7]}$.

Initial management involves rapid assessment of maternal cardiovascular status and the rate of continuing blood loss, followed by fetal assessment. IV access with a 16 Guage cannula should be established in all women, regardless of the degree of bleeding or vital observations. Baseline investigations, including haemoglobin estimation, blood cross matching and in women with heavy bleeding, clotting studies are indicated. Fluid replacement with crystalloid is appropriate initially; this may be supplemented with a calcified in the presence of heavier blood loss. In women requiring delivery because of heavy bleeding, transfusion of cross matched blood should begin as soon as possible, because further severe haemorrhage at the time of $\mathrm{C} / \mathrm{S}$ is likely ${ }^{[8]}$.

Transfusion to maintain maternal haemoglobin levels is also essential in women with active bleeding in whom immediate delivery is not considered necessary, because of the risk of heavier bleeding, concerns regarding the transmission of human immuno deficiency virus (HIV) have resulted in more conservative transfusion policies in obstetrics. The risk of transmission has been estimated as 1 in $1,53,000$ and is in this situation vastly outweighed by the risk of serious morbidity secondary to further bleeding.

Fetal hypoxia related to a bleeding episode of placenta praevia is less common than that associated with placental abruption. Fetal distress may occur as a result of placental separation, developing fetal anaemia or labour. Monitoring of FHR should be 
commenced at viable gestations and delivery to be undertaken if evidence of suspected fetal compromise develops ${ }^{[9]}$.

Bleeding from placenta praevia is usually associated with uterine activity. A vicious cycle occurs where small changes in cervical effacement and dilatation, which occurs as a physiological phenomenon in many women in the third trimester, precipitate placental bleeding. This in turn stimulates the release of Prostaglandins from the lower segment decidua and thereby the onset of at contraction, which will aggravate the amount of bleeding by exerting further shearing forces on the placenta at the level of the cervix. The initial uterine activity is usually not perceived by woman herself.

Scanning technique used is important. Placenta in the mid trimester scan can be diagnosed as early as $9^{\text {th }}$ week of Intra uterine life has a relatively homogenous parenchymal structure. The combined scanning technique, increases the echoes and improves the quality of image. In a typical longitudinal plane sonogram, placenta appears as semilunar areas with multiple echoes bordered on the maternal side by uterus and fetal side by chorionic plate. The lower pelvic brim is a line joining the pubic symphysis and sacrum arbitrarily ${ }^{[10]}$.

\section{Conclusion}

Placental anomalies were present in 4 (4.76 percent) cases, out of which, 2 cases ( 2.38 percent) were of adherent placenta.

\section{References}

1. Cotton D, Read J, Paul R. Quilligan E. The conservative aggressive management of placenta praevia, Am J. Obstet Gynaecol. 1980;137:687-695.

2. Welch C, Make peace P, Walkenshaw S. Management of pregnancies complicated by Rhesus (D) Antibodies Br. J. Hosp Med. 1993;49:813-816.

3. Miller DA, Cholett JA, Goodwin TM, Clinical Risk factors in placenta praevia-placenta accreta Am J Obstet Gynaecol. 1997; 177:210-4.

4. Das Chandana, Mukherjee Partha, Choudhary Nilanjana, Majhi Arup Kumar Simha KK: Isthmic cervical apposition suture an effective method to control PP during C-section for PP: J Obstet Gynecol India. 2005;55(4):322-324.

5. Druzin M. Packing of the lower segment for control of post cesarean bleeding in instances of placenta praevia, Surg Gynecol Obstet 1989:169;543-545.

6. Macafee $\mathrm{CH}$, Millar WG, Harley G, Maternal and Foetal Mortality in placenta praevia. J. Obstet Gynecol Br common with. 1962;69:203-212.

7. Mcshane PM. Heydl PS, Epstein MF Maternal and Perinatal Morbidity resulting from Placenta praevia. Obstet Gynecol 1985; 65: 176-182.

8. Brenner W, Edelman D. Hendricks C. Characteristics of patients with placenta praevia and results of expectant management Am J. Obstet Gynecol. 1978;132:180-189.

9. Das B Antepartum Hemorrhage's in 3 decades J. Obstet Gynecol India. 1975;25:636-41.

10. Tariq Khashoggi, Arab Board: Maternal and neonatal outcome in Major placenta praevia. Ann Saudi Med. 1995;15:4. 